\title{
ESTIMASI BEBAN PENDINGIN UNTUK GEDUNG HEMAT ENERGI MENGGUNAKAN JARINGAN SARAF TIRUAN
}

\author{
Muhammad Redho Darmawan \\ Fakultas Sains dan Komputer, Program Studi Ilmu Komputer \\ Universitas Pertamina \\ Email: redho.darmawan@universitaspertamina.ac.id \\ Fitri Karimah \\ Fakultas Sains dan Komputer, Program Studi Ilmu Komputer \\ Universitas Pertamina \\ Email: fitri.karimah@universitaspertamina.ac.id \\ Meredita Susanty \\ Fakultas Sains dan Komputer, Program Studi Ilmu Komputer \\ Universitas Pertamina \\ Email: meredita.susanty@universitaspertamina.ac.id \\ Ade Irawan \\ Fakultas Sains dan Komputer, Program Studi Ilmu Komputer \\ Universitas Pertamina \\ Email: ade.irawan@universitaspertamina.ac.id
}

\begin{abstract}
ABSTRAK
Untuk mencapai target konservasi energi sebesar 17\% di tahun 2025 pemerintah menerapkan aturan manajemen energi bagi industri/penguna energi lebih besar sama dengan 6000 TOE. Di sektor bangunan gedung di Indonesia, konsumsi energi terbesar adalah penggunaan pendingin udara. Salah satu cara untuk melakukan penghematan dalam tata udara dengan menggunakan perangkat yang hemat listrik tanpa mengorbankan kenyamanan penghuni gedung. Penelitian ini menggunakan metode jaringan saraf tiruan untuk memprediksi beban pendingin optimum untuk suatu gedung berdasarkan 8 karakteristik bangunan. Model yang dibuat memberikan hasil yang baik dengan nilai nilai loss $0,4-1,1 \%$.
\end{abstract}

Kata kunci: deep learning, jaringan syaraf tiruan, konservasi energi, gedung ramah lingkungan

\begin{abstract}
To achieve the energy conservation target of $17 \%$ in 2025, the government applies energy management regulations for industries/energy users greater than 6000 TOE. In the building sector in Indonesia, the most significant energy consumption is the use of air conditioners. One way to conserve energy from HVAC usage is by using electricity efficient devices without sacrificing the comfort of building occupants. This study uses an artificial neural network method to predict the optimum cooling load for a building based on eight building characteristics. The model shows a promising result with loss around 0.4-1.1\%.
\end{abstract}

Keywords: deep learning, neural network, energy conservation, green building

\section{PENDAHULUAN}

Ketersedian dan ketahanan energi sangat penting bagi suatu negara karena energi merupakan komponen utama dalam memproduksi barang dan jasa. Di Indonesia, pengelolaan energi lebih berfokus 
pada penyediaan dan pengusahaan energi dibandingkan konservasi energi. Penggunaan energi di Indonesia termasuk boros baik di sektor industri, transportasi dan bangunan gedung [1].

Pemerintah melalui Kebijakan Energi Nasional (KEN) menetapkan target konservasi energi untuk dapat mengurangi intensitas energi sebesar $1 \%$ per-tahun dan mencapai penghematan energi final sebesar $17 \%$ pada 2025 [2]. Guna mencapai target KEN tersebut EBTKE telah melakukan berbagai kegiatan diantaranya dengan menerapkan manajemen energi bagi industri/pengguna energi lebih besar sama dengan 6.000 TOE (ton oil equivalen) di sektor industri/bangunan. Selain itu, Rencana Umum Energi Nasional (RUEN) [3] telah mendetailkan beberapa rencana kerja yang seharusnya dilaksanakan. Namun, beberapa rencana kerja yang seharusnya terbit pada tahun 2019 banyak yang masih belum diterbitkan. Salah satunya adalah Penyusunan Permen Perindustrian terkait perencanaan kebutuhan dan efisiensi energi sektor industri [4].

Berbagai upaya untuk mencapai target tersebut belum terlihat dengan jelas. Pada tahun 2018 capaian konservasi energi hanya sekitar 9\% [5], [6]. Bangunan dan gedung di Indonesia adalah pengguna energi terbesar ketiga, dengan porsi sekitar 30 persen dari total konsumsi energi nasional. Jika tidak dikelola dengan baik, konsumsi energi dari gedung dan bangunan berpotensi meningkat hingga 40 persen dari total konsumsi energi pada tahun 2030 [7]. Namun, jika dikelola dengan baik memiliki potensi penghematan energi sebesar 42 juta setara barel minyak [5]. Penelitian ini bertujuan membantu pemangku kepentingan untuk mendesain bangunan hemat energi. Di sektor bangunan gedung, proporsi konsumsi energi di sektor bangunan gedung tertinggi adalah penggunaan pendingin udara sebesar 52\% [8]. Untuk melakukan penghematan dari sisi tata udara, perlu ditentukan kapasitas pendingin yang optimum tanpa mengorbankan kenyamanan penghuni gedung terhadap suhu dalam ruangan. Beban pendingin bisa dihitung berdasarkan karakteristik bangunan dan ruang, cuaca, dan pemanfaatan ruangan. Sebagian besar penelitian terdahulu di bidang ini menggunakan simulasi [9], [10]. Namun belakangan sudah semakin banyak penelitian lainnya menggunakan pendekatan machine learning karena kecepatan yang lebih baik. Teknik machine learning yang digunakan pada penelitian sebelumnya beragam, seperti support vector machine [11], [12], regresi [13], dan jaringan saraf tiruan (JST) [14]. Untuk melakukan prediksi, model-model tersebut menggunakan 3 hingga 6 atribut yang berbeda.

Penelitian ini menggunakan 8 atribut [15]; relative compactness, surface area, wall area, roof area, overall height, orientation, glazing area, glazing area distribution untuk memprediksi beban pendingin di gedung komersil menggunakan teknik deep neural network.

\section{METODOLOGI PENELITIAN}

Penelitian ini mengikuti tahapan yang dijelaskan pada gambar Gambar 1 yang terdiri dari pengumpulan data, analisis data, pra-pengolahan data, pembuatan model dengan menggunakan teknik jaringan saraf tiruan (JST), penyesuaian parameter pada model, dan validasi untuk model yang dibuat..

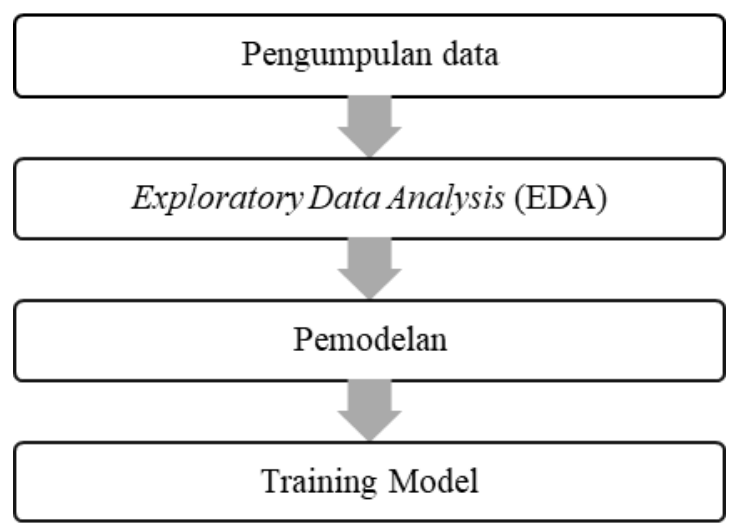

Gambar 1. Metodologi Penelitian 
Dataset dalam penelitian ini terdiri dari 8 atribut input dan 1 atribut output seperti dijelaskan pada Tabel 1. Pada tabel 1, input variabel atau fitur diberi nama $\mathrm{x}$ dan output variabel diberi nama y. Dataset yang didapat dibagi menjadi 2 data training dan data testing dengan perbandingan 4:1.

Tabel 1. Input dan Output Variabel

\begin{tabular}{cl}
\hline Atribut & \multicolumn{1}{c}{ Keterangan } \\
\hline X1 & Relative Compactness \\
\hline X2 & Surface Area \\
\hline X3 & Wall Area \\
\hline X4 & Roof Area \\
\hline X5 & Overall Height \\
\hline X6 & Orientation \\
\hline X7 & Glazing Area \\
\hline X8 & Glazing Area Distribution \\
\hline Y1 & Heating Load \\
\hline
\end{tabular}

Selanjutnya dilakukan analisis terhadap data yang ada. Exploratory Data Analysis (EDA) merupakan investigasi awal terhadap data untuk menemukan pola, anomali menggunakan pendekatan statistika dan representasi grafis. Pada tahapan ini dilakukan pemeriksaan tipe data, rentang nilai, dan kelengkapan data pada setiap fitur. Selain itu juga dilakukan pemeriksaan untuk melihat korelasi setiap fitur terhadap output serta tingkat korelasi setiap fitur terhadap output. Jika korelasi antara fitur dan output linear, maka tingkat korelasi diukur menggunakan Pearson's Rank Correlation [16]. Sedangkan jika korelasinya tidak linear, maka digunakan Spearman Rank Correlation [17].

Pada tahapan pra-pengolahan data dilakukan normalisasi menggunakan min-max scaling jika hasil exploratory data analysis menunjukkan perbedaan rentang nilai untuk tiap fitur. Min-max scaling melakukan perubahan linear terhadap data asli [16]. Setiap nilai akan dipetakan menjadi nilai baru dalam range nilai yang sudah ditentukan menggunakan persamaan (1). Metode ini dipilih karena tetap mempertahankan relationship diantara data asli.

$$
\begin{aligned}
& v^{v}=\frac{v-\min _{A}}{\max _{A}-\min _{A}}\left(\max _{A}-\operatorname{mmax}_{B}\right)+\operatorname{mmin}_{A} \\
& \sigma(z)=1 /(1+\exp (-z)) \\
& f(x)=\max (0, x) \\
& M A E=\frac{1}{n} \sum_{i=1}^{n}\left|y_{i}-x_{i}\right|
\end{aligned}
$$

Model untuk memprediksi beban pendingin menggunakan teknik deep neural network dimana model akan memiliki beberapa hidden layer seperti ditunjukkan pada Gambar 2. Hasil EDA akan menentukan activation function yang digunakan dalam model ini. Jika korelasi data terhadap output linear, model menggunakan fungsi sigmoid pada persamaan (2). Sebaliknya, saat korelasi tidak linear, digunakan activation function ReLU pada persamaan (3) [18]. Tujuan utama dari penggunaan fungsi aktivasi ini adalah untuk membentuk non-linearity (ketidaklinieran) pada neural network. Tanpa adanya fungsi aktivasi, neural network hanya akan melakukan transformasi linier dari input ke output. 


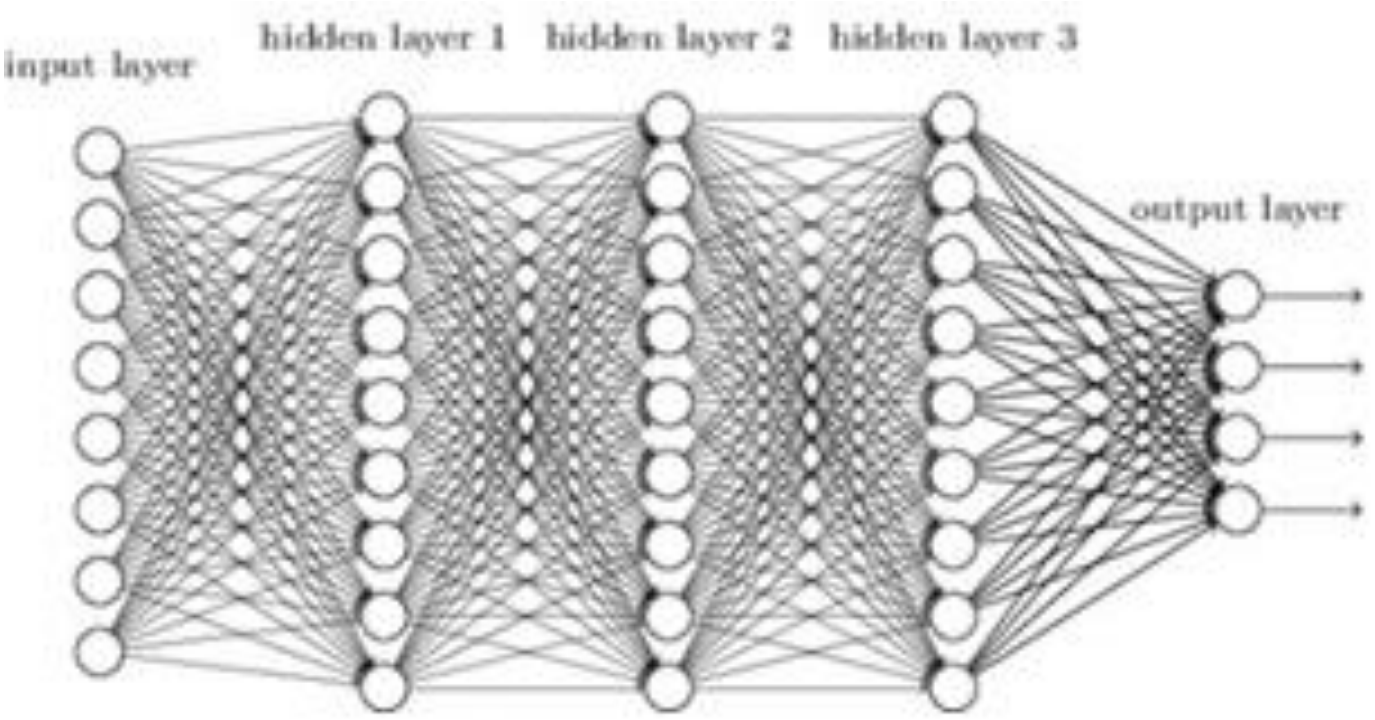

Gambar 2. Arsitektur JST [19]

Training merupakan proses mencari nilai yang memiliki error paling rendah. Nilai error diperoleh melalui persamaan loss function, semakin kecil nilai loss dari suatu model, maka semakin tinggi akurasi yang dihasilkan saat training. Untuk mengevaluasi performa model dalam penelitian ini digunakan loss function Mean Absolute Error pada persamaan 4 [20].

\section{HASIL DAN PEMBAHASAN}

Dataset yang digunakan berjumlah 768 data dan 8 fitur, diambil dari repository yang disediakan secara umum [21]. Dari 768 data, dibagi menjadi 2 kelompok secara acak dengan proporsi 4:1 menjadi 614 data training dan 154 data test.

Analisis data dilakukan terhadap keseluruhan dataset. Analisis pertama yang dilakukan adalah memeriksa tipe data, rentang nilai, dan kelengkapan data pada setiap fitur. Semua data menggunakan tipe data float dan tidak ada data yang kosong. Hasil pemeriksanaan secara statistik pada Tabel 2 menunjukkan bahwa ada perbedaan rentang nilai untuk tiap fitur.

Tabel 2. Analisis Statistik

\begin{tabular}{cccccccc}
\hline & mean & std & min & Q1 & Q2 & Q3 & max \\
\hline $\mathrm{X} 1$ & 0.76 & 0.11 & 0.62 & 0.68 & 0.75 & 0.83 & 0.98 \\
\hline $\mathrm{X} 2$ & 671.71 & 88.09 & 514.5 & 606.38 & 673.75 & 741.13 & 808.5 \\
\hline $\mathrm{X} 3$ & 318.5 & 43.63 & 245 & 294 & 318.5 & 343 & 416.5 \\
\hline $\mathrm{X} 4$ & 176.6 & 45.17 & 110.25 & 140.88 & 183.75 & 220.5 & 220.5 \\
\hline $\mathrm{X} 5$ & 5.25 & 1.75 & 3.5 & 3.5 & 5.25 & 7 & 7 \\
\hline $\mathrm{X} 6$ & 3.5 & 1.12 & 2 & 2.75 & 3.5 & 4.25 & 5 \\
\hline $\mathrm{X} 7$ & 0.23 & 0.13 & 0 & 0.1 & 0.25 & 0.4 & 0.4 \\
\hline $\mathrm{X} 8$ & 2.81 & 1.55 & 0 & 1.75 & 3 & 4 & 5 \\
\hline $\mathrm{Y} 1$ & 24.59 & 9.51 & 10.9 & 15.62 & 22.08 & 33.13 & 48.03 \\
\hline
\end{tabular}

Karena rentang nilai yang beragam, dilakukan normalisasi terhadap data menggunakan teknik minmax scaling. Hasil normalisasi ditunjukkan pada Tabel 3.

Berdasarkan data yang sudah dinormalisasi diperiksa korelasi antara setiap fitur terhadap output dengan menggunakan scatter plot pada Gambar 3. Dari visualisasi data yang ditampilkan di Gambar 3 bisa 
dilihat bahwa korelasi antara setiap fitur atau input terhadap output tidak linear. Selanjutnya dilakukan pemeriksaan seberapa besar korelasi masing-masing fitur terhadap output. Karena hubungan antara setiap fitur tidak linear terhadap output, untuk memeriksa tingkat korelasi digunakan Spearman rank correlation coefficient. Gambar 4 menunjukkan tingkat korelasi dengan gradasi warna, warna yang terang menunjukkan korelasi positif sedangkan warna gelap menunjukkan korelasi negatif. Dari gambar tersebut bisa disimpulkan bahwa fitur X1, X2, X3, X4, X5 memiliki korelasi yang kuat terhadap output. X1, X3 dan X5 memiliki korelasi positif sedangkan X2 dan X4 memiliki korelasi negatif.

Tabel 3. Hasil Normalisasi

\begin{tabular}{lccccccc}
\hline & mean & std & min & Q1 & Q2 & Q3 & max \\
\hline $\mathrm{X} 1$ & 0.4 & 0.29 & 0 & 0.17 & 0.36 & 0.58 & 1 \\
\hline $\mathrm{X} 2$ & 0.53 & 0.3 & 0 & 0.31 & 0.54 & 0.77 & 1 \\
\hline $\mathrm{X} 3$ & 0.43 & 0.25 & 0 & 0.29 & 0.43 & 0.57 & 1 \\
\hline $\mathrm{X} 4$ & 0.6 & 0.41 & 0 & 0.28 & 0.67 & 1 & 1 \\
\hline $\mathrm{X} 5$ & 0.5 & 0.5 & 0 & 0 & 0.5 & 1 & 1 \\
\hline $\mathrm{X} 6$ & 0.5 & 0.37 & 0 & 0.25 & 0.5 & 0.75 & 1 \\
\hline $\mathrm{X} 7$ & 0.59 & 0.33 & 0 & 0.25 & 0.63 & 1 & 1 \\
\hline $\mathrm{X} 8$ & 0.56 & 0.31 & 0 & 0.35 & 0.6 & 0.8 & 1 \\
\hline $\mathrm{Y} 1$ & 0.37 & 0.26 & 0 & 0.13 & 0.3 & 0.6 & 1 \\
\hline
\end{tabular}

Model yang dibangun terdiri dari 1 output layer (180 nodes), 3 hidden layer yang masingmasing terdiri dari 270 nodes, dan 1 output layer berisi 1 nodes yang mewakili nilai pendingin. Setiap layer menggunakan activation function ReLU. Training model dilakukan terhadap data training yang berjumlah 614 data sebanyak 1000 kali. Selama model berjalan, algoritma optimasi Adam digunakan untuk memperbarui weight berdasarkan data training. Untuk menghitung loss digunakan loss function mean absolute error. Hasil training menunjukkan loss sebesar 0,4\%. Hasil ini menunjukkan performa yang baik, namun perlu dilakukan validasi untuk memeriksa apakah model yang dihasilkan overfit.
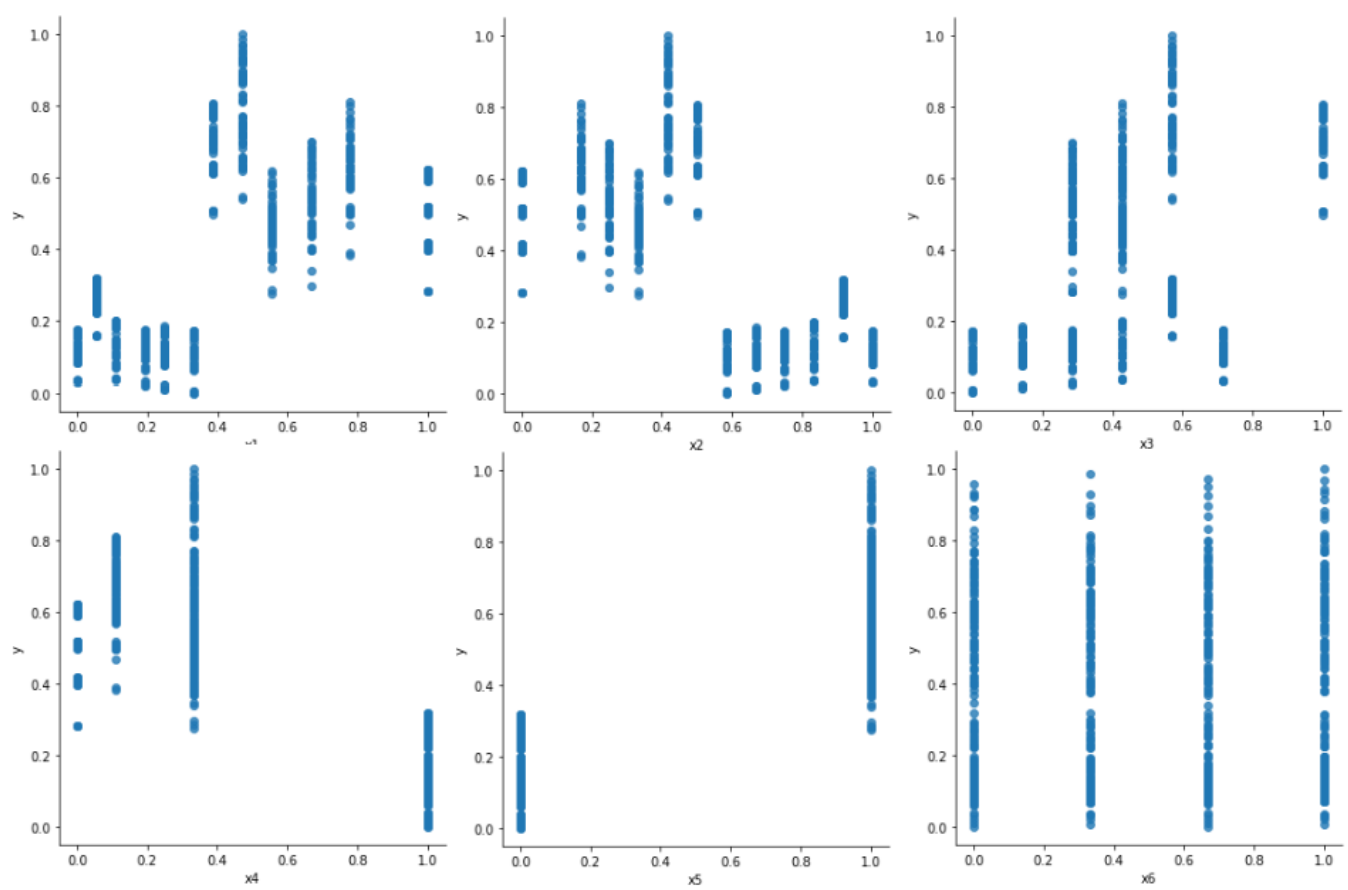

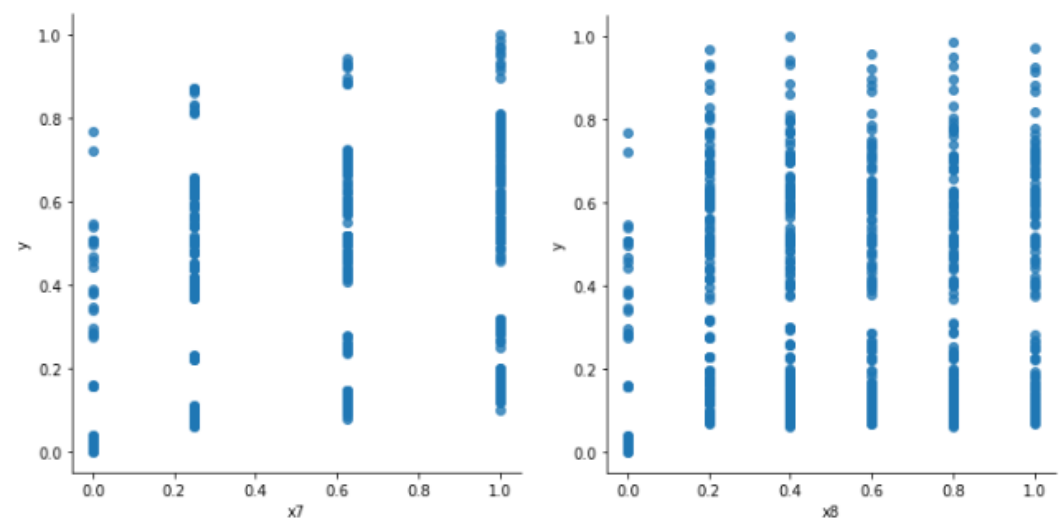

\section{Gambar 3. Korelasi Setiap Fitur terhadap Output Beban Pendingin}

Validasi digunakan menggunakan data testing sebanyak 154 data yang sudah dinormalisasi. Model dijalankan terhadap data testing. Hasil validasi menunjukkan sedikit penutunan dengan nilai loss sebesar $1,1 \%$. Nilai loss terhadap data training dan validation digambarkan dalam grafik seperti ditunjukkan pada Gambar 5 dan 6. Pada kedua grafik tersebut bisa dilihat antara model train dan validation relatif mirip. Hal ini menunjukkan bahwa model tidak mengalami overfitting.

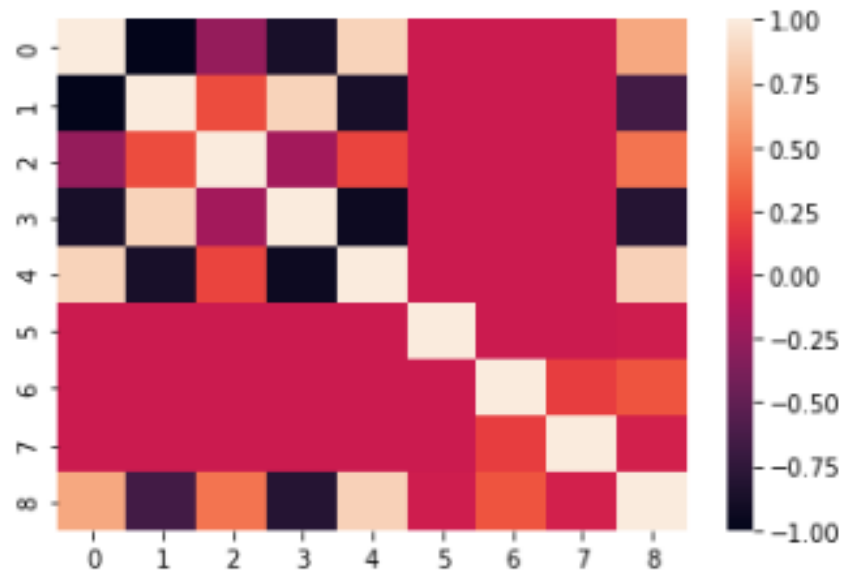

Gambar 4. Tingkat Korelasi Setiap Fitur terhadap Output

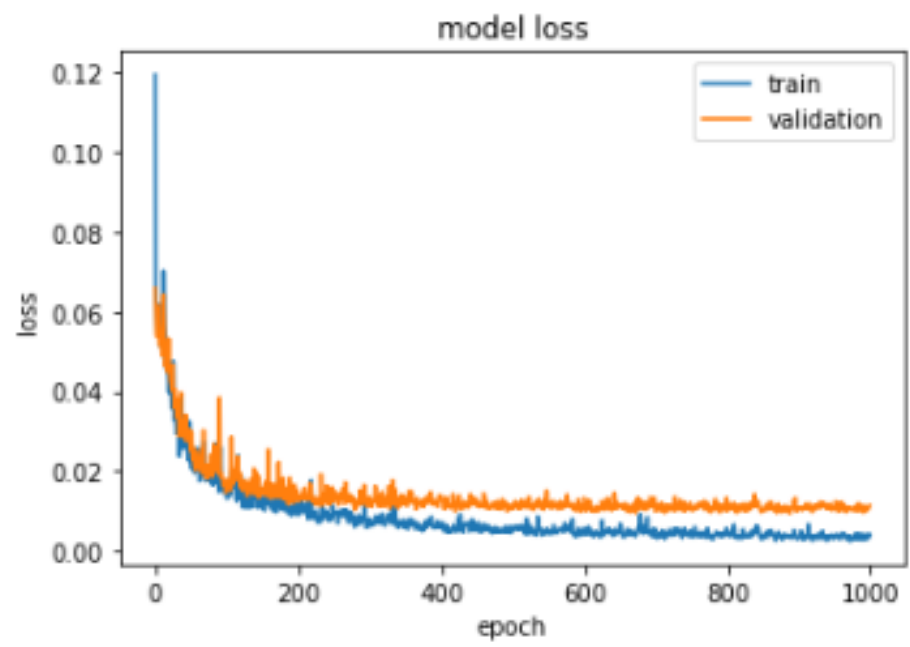




\section{Gambar 5. Loss Pada Model}

Nilai loss pada Gambar 5 yang semakin lama semakin mendekati 0 (turun) menunjukkan bahwa prediksi yang dilakukan oleh sistem semakin baik. Sistem belajar dan melakukan perbaikan nilai weight yang digunakan untuk fitting network dengan baik. Bisa dilihat juga bahwa nilai loss mulai melandai pada iterasi ke 200 dan relatif stabil pada iterasi ke 600. Jika ingin mempercepat jalannya simulasi pada model, parameter epoch pada model bisa diturunkan menjadi 600 .

\section{KESIMPULAN}

Mendapatkan nilai beban pendingin yang optimum untuk bangunan gedung diharapkan dapat secara signifikan meningkatkan capain konservasi energi. Dengan memperhitungkan delapan fitur yang mewakili karakteristik bangunan, model melakukan prediksi beban pendingin gedung yang optimal. Model yang dibangun menunjukkan hasil yang baik, nilai loss yang semakin kecil dan nilai akurasi yang semakin meningkat seiring dengan jumlah iterasi menunjukkan bahwa model belajar dan hasil pembelajaran yang dilakukan oleh model bekerja dengan baik. Selanjutnya dapat dibuat aplikasi sederhana seperti kalkulator penghitung beban pendingin gedung dengan memanfaatkan model yang sudah dibuat ini.

\section{DAFTAR PUSTAKA}

[1] "Para Pengelola Gedung Didorong Lakukan Efisiensi Energi - Nasional Tempo.co,” 2019. [Online]. Available: https://nasional.tempo.co/read/1200821/para-pengelola-gedungdidorong-lakukan-efisiensi-energi. [Accessed: 15-May-2020].

[2] Indonesian Government, "Indonesian Government Law No 79 In 2014 About National Energy Policy," p. 8, 2014.

[3] Ministry of Energy and Mineral Resources, "Presidential Regulation Number 22 of 2017 on the General Planning for National Energy (RUEN)." 2017.

[4] "Pekerjaan Rumah Pemerintah Untuk Akselerasi Penerapan Konservasi Energi di Indonesia ICEL,” 2019. [Online]. Available: https://icel.or.id/isu/pekerjaan-rumah-pemerintah-untukakselerasi-penerapan-konservasi-energi-di-indonesia/. [Accessed: 31-May-2020].

[5] "Konservasi Energi Nasional Baru Mencapai 9\% - Dunia Energi," 2019. [Online]. Available: https://www.dunia-energi.com/konservasi-energi-nasional-baru-mencapai-9/. [Accessed: 31May-2020].

[6] Direktorat Konservasi Energi Kementerian ESDM, "Data \& Informasi - Konservasi Energi 2018," p. 61, 2019.

[7] M. K. Alfarizi and E. Prima, "Studi: Bangunan Gedung Hijau Hemat 30-80 Persen Biaya Tekno Tempo.co," 21-Feb-2019. [Online]. Available: https://tekno.tempo.co/read/1177826/studi-bangunan-gedung-hijau-hemat-30-80-persenbiaya/full\&view=ok. [Accessed: 15-May-2020].

[8] "User Guide For Commercial Sector." Indonesian Institute for Energy Economics, 2014.

[9] A. Yezioro, B. Dong, and F. Leite, "An applied artificial intelligence approach towards assessing building performance simulation tools," Energy Build., vol. 40, no. 4, pp. 612-620, Jan. 2008.

[10] D. B. Crawley, J. W. Hand, M. Kummert, and B. T. Griffith, "Contrasting the capabilities of building energy performance simulation programs,” Build. Environ., vol. 43, no. 4, pp. 661673, Apr. 2008.

[11] B. Dong, C. Cao, and S. E. Lee, "Applying support vector machines to predict building energy consumption in tropical region," Energy Build., vol. 37, no. 5, pp. 545-553, May 2005.

[12] Q. Li, Q. Meng, J. Cai, H. Yoshino, and A. Mochida, “Applying support vector machine to predict hourly cooling load in the building," Appl. Energy, vol. 86, no. 10, pp. 2249-2256, Oct. 2009. 
[13] T. Catalina, J. Virgone, and E. Blanco, "Development and validation of regression models to predict monthly heating demand for residential buildings," Energy Build., vol. 40, no. 10, pp. 1825-1832, Jan. 2008.

[14] J. Zhang and F. Haghighat, "Development of Artificial Neural Network based heat convection algorithm for thermal simulation of large rectangular cross-sectional area Earthto-Air Heat Exchangers,” Energy Build., vol. 42, no. 4, pp. 435-440, Apr. 2010.

[15] W. Pessenlehner and A. Mahdavi, "Building Morphology, Transparence, and Energy Performance," in Eight International IBPSA Conference, 2003.

[16] M. Kamber, Data Mining : Concepts and Techniques, Second. Elsevier, 2016.

[17] C. Xiao, J. Ye, R. M. Esteves, and C. Rong, "Using Spearman's correlation coefficients for exploratory data analysis on big dataset," Concurr. Comput. Pract. Exp., vol. 28, no. 14, pp. 3866-3878, Sep. 2016.

[18] S. Sharma, “Activation Functions in Neural Networks - Towards Data Science,” 2017. [Online]. Available: https://towardsdatascience.com/activation-functions-neural-networks1cbd9f8d91d6. [Accessed: 05-Jun-2020].

[19] L. Anastasia Kyrykovych, "Deep Neural Networks.” [Online]. Available: https://www.kdnuggets.com/2020/02/deep-neural-networks.html. [Accessed: 05-Jun-2020].

[20] C. Willmott and K. Matsuura, "Advantages of the mean absolute error (MAE) over the root mean square error (RMSE) in assessing average model performance," Clim. Res., vol. 30, pp. 79-82, Dec. 2005.

[21] A. Xifara and A. Tsanas, "UCI Machine Learning Repository: Energy efficiency Data Set." [Online]. Available: https://archive.ics.uci.edu/ml/datasets/Energy+efficiency. [Accessed: 04Jun-2020]. 